\title{
Alendronate use and bone mineral density gains in women with moderate-severe (stages 3B-5) chronic kidney disease: an open cohort multivariable and propensity score analysis from Funen, Denmark
}

\author{
M. Sanni Ali ${ }^{1,2,3}$. Martin Ernst ${ }^{4,5}$. Danielle E. Robinson ${ }^{2} \cdot$ Fergus Caskey $^{6}$ - Nigel K. Arden ${ }^{7,8} \cdot$ Yoav Ben-Shlomo $^{6}$. \\ Mads Nybo ${ }^{9}$. Katrine H. Rubin ${ }^{4}$. Andrew Judge ${ }^{6,7,8}$. Cyrus Cooper ${ }^{7,8} \cdot$ M. K. Javaid ${ }^{7,8}$ • Anne P. Hermann ${ }^{10}$. \\ Daniel Prieto-Alhambra $2,8,11$
}

Received: 21 August 2019 / Accepted: 30 April 2020

(C) The Author(s) 2020, corrected publication 2021

\begin{abstract}
Summary Bisphosphonates are contraindicated in moderate-to-severe chronic kidney disease patients. However, they are used to prevent fragility fractures in patients with impaired kidney function, despite a lack of evidence on their effects on bone density in these patients. We demonstrated that Alendronate had a positive effect on bone in these patients.

Purpose This study aimed to assess the association between alendronate use and bone mineral density (BMD) change in subjects with moderate-severe chronic kidney disease (CKD).

Methods We created a cohort of CKD stage 3B-5 patients by linking all DXA-based measurements in the Funen area, Denmark, to biochemistry, national health registries and filled prescriptions. Exposure was dispensation of alendronate and the outcome was annualized percentage change in BMD at the femoral neck, total hip and lumbar spine. Individuals were followed from first BMD to the latest of subsequent DXA measurements. Alendronate non-users were identified using incidence density sampling and matched groups were created using propensity scores. Linear regression was used to estimate average differences in the annualized BMD.

Results Use of alendronate was rare in this group of patients: propensity score matching (PSM) resulted in 71 alendronate users and 142 non-users with stage 3B-5 CKD (as in the 1 year before DXA). Whilst alendronate users gained an average $1.07 \%$ femoral neck BMD per year, non-users lost an average of $1.59 \%$ per annum. The PSM mean differences in annualized BMD were $+2.65 \%(1.32 \%, 3.99 \%),+3.01 \%(1.74 \%, 4.28 \%)$ and $+2.12 \%(0.98 \%, 3.25 \%)$ at the femoral neck, total hip and spine $\mathrm{BMD}$, respectively, all in favour of alendronate users.
\end{abstract}

M. Sanni Ali and Martin Ernst contributed equally to this work.

Daniel Prieto-Alhambra

daniel.prietoalhambra@ndorms.ox.ac.uk

1 Faculty of Epidemiology and Population Health, Department of Non-communicable Disease Epidemiology, London School of Hygiene and Tropical Medicine, London, UK

2 Center for Statistics in Medicine, Nuffield Department of Orthopaedics, Rheumatology and Musculoskeletal Sciences, University of Oxford, Oxford, UK

3 Department of Public Health, Saint Paul Hospital Millennium Medical College, Addis Ababa, Ethiopia

4 OPEN, Department of Health, University of Southern Denmark, Odense, Denmark

5 Department of Public Health, Clinical Pharmacology and Pharmacy, University of Southern Denmark, Odense, Denmark
6 Population Health Sciences, Bristol Medical School, University of Bristol, Bristol, UK

7 Nuffield Department of Orthopaedics, Rheumatology and Musculoskeletal Sciences, University of Oxford, Oxford, UK

8 MRC Lifecourse Epidemiology Unit, Southampton, UK

9 Department of Clinical Biochemistry and Pharmacology, Odense University Hospital, Odense, Denmark

10 Department of Endocrinology, Odense University Hospital, Odense, Denmark

11 GREMPAL Research Group (Idiap Jordi Gol Primary Care Research Institute) and CIBERFes, Universitat Autonoma de Barcelona, Barcelona, Spain 
Conclusion In a real-world cohort of women with stage 3B-5 CKD, use of alendronate appears associated with a significant improvement of 2-3\% per year in the femoral neck, total hip and spine BMD. More data are needed on the anti-fracture effectiveness and safety of bisphosphonate therapy in moderate-severe CKD.

Keywords Alendronate $\cdot$ Bone mineral density $\cdot$ Chronic kidney disease $\cdot$ Osteoporosis $\cdot$ Incidence density sampling $\cdot$ Propensity score

\section{Introduction}

Chronic kidney disease (CKD) is a multi-factorial disease associated with a range of metabolic diseases and complications. The prevalence of these complications increases rapidly in patients with stage $3 \mathrm{~B}$, an estimation of glomerular filtration rate (eGFR) below $45 \mathrm{ml} / \mathrm{min} / 1.73 \mathrm{~m}^{2}$ (1). It is also an independent risk factor for osteoporosis. More than one in four people with osteoporosis have moderate or severe CKD (2). CKD has been shown to predict not only low bone mass due to accelerated bone loss (3) but also fracture risk, with a doubled risk in patients with stage 3 CKD (eGFR between 30 and $59 \mathrm{ml} / \mathrm{min} / 1.73 \mathrm{~m} 2)(4)$; a 2.5 - to 3 -fold risk in those with stage 3B CKD (4); and a four-times higher fracture incidence amongst patients with stage 4 CKD (eGFR between 15 and 29 $\mathrm{ml} / \mathrm{min} / 1.73 \mathrm{~m} 2)(5,6)$ or in renal replacement therapy $(7,8)$.

Osteoporosis may develop in patients with a reduced eGFR due to age-related decrease in renal function or in patients with intrinsic renal disease (1). Patients with CKD due to intrinsic renal disease often have additional risk factors for osteoporosis such as glucocorticoid use, hyperparathyroidism, and vitamin D deficiency (9). Bone mass or bone mineral density (BMD) is a recognized key determinant of future fracture risk in postmenopausal women (10) and patients with CKD, next to bone microarchitecture, bone geometry and rate of turnover (11). Measurement of BMD at the lumbar spine, femur neck or total hip by dual-energy X-ray absorptiometry (DEXA) is the standard method for diagnosis of osteoporosis and evaluating fracture risk, particularly in non-CKD patients. However, its significance and interpretation in CKD patients have been controversial due to a combination of CKDinduced changes in bone and mineral metabolism (1). Recently, several studies have shown that BMD is a good predictor of fracture risk in CKD stages 3-5; as a result, the 2017 Kidney Disease Improving Global Outcomes (KDIGO) guideline recommended systematic BMD measurement in CKD patients (12-14). BMD measurement is often assessed before anti-fracture treatment decisions are made; this is in part due to the fact that therapeutic trials in osteoporosis usually require a low BMD value as an entry criterion. Hence, medications are often licensed for use in patients below a given BMD threshold. In addition, BMD is also monitored as a surrogate marker to evaluate the response of an individual patient to treatment as well as the efficacy of a treatment in clinical trials (15-18).
The most important clinical goal of osteoporosis treatment is the reduction in fracture risk, due to high morbidity and mortality associated with it, especially in elderly people. Whilst there are effective therapies to reduce the risk of osteoporotic fracture, the use of oral bisphosphonates (i.e. first-line anti-osteoporosis therapies) is restricted in patients with CKD for several reasons. First, there are safety concerns related to the risk of bisphosphonates worsening kidney function and other adverse events which are already increased in patients with CKD such as severe hypocalcaemia or hyperphosphatemia, or acute kidney injury (9). Second, given the biological mechanism of how CKD weakens bone differs from osteoporosis, it is far from established that bisphosphonates will have a similar beneficial effect in improving BMD. Importantly, participants in these trials with CKD are likely to be healthier and have less comorbidities compared with patients with CKD in the real-world setting. This leaves moderate-severe CKD patients with a very high fracture risk effectively untreatable. In addition, the relationship between changes in BMD during treatment with oral bisphosphonates and fracture risk is still less clear since the numbers of patients with moderate or severe $\mathrm{CKD}$ recruited for the pivotal trials were low (15-17, 19-21). However, clinical trial participants with higher BMD gains on oral bisphosphonate therapy had a significantly lower risk of fracture than participants with no change or a reduction in BMD (20). Hence, BMD is an accepted surrogate marker in bridging studies of anti-osteoporosis treatments (22) to test different dosing regimens (23) and efficacy in other populations such as men (24) and in patients taking glucocorticoids (25).

The relationship between BMD change and fracture risk in postmenopausal osteoporosis versus bone fragility in CKD may differ given the different aetiopathology of bone fragility in CKD (26) with particular reference to potential adynamic bone disease. The aim of this study was to examine the association between bisphosphonate use and changes in BMD over time in subjects with moderate-to-severe CKD (stages $3 \mathrm{~B}, 4$ and 5).

\section{Methods}

\section{Data source}

We used the Odense University Hospital Database (OUHD) which holds DXA-measured BMD data for the whole of the 
Funen region, the second-largest island of Denmark, comprising 36,024 individuals examined between August 1990 and February 2015. Serum creatinine is part of the routine panel of blood tests performed at the Odense University Hospital as part of osteoporosis care. Primary care practices and hospitals in this Danish region use the same clinical biochemistry laboratory, making all biochemistry values (including serum creatinine tests) available for this study. We were able to calculate the eGFR for participants in this cohort using the CKD-EPI formula (27). Pharmacy drug dispensations of primary and secondary care prescriptions can be tracked back to 1995 from the Danish Prescriptions Register and linked using unique national patient identifiers to OUHD. Pharmacy dispensations are recorded using Anatomic Therapeutic Classification (ATC) codes.

The Open Patient Data Exploratory Network (OPEN) provides a unique platform for linking clinical, dispensation and biochemistry data. It is an approved Statistics Denmark institutional partner for linking to diagnoses and comorbidity recorded using ICD-10 codes in Danish hospital records. The Network has previously been used to link clinical biochemistry to fracture outcomes in numerous studies (28-32). Ad hoc extraction and linking to renal function from the Odense University Hospital clinical biochemistry database was done as part of this study using a similar approach. In the OUHD, $30 \%$ of individuals examined (over 10,000 subjects) were recommended osteoporosis treatment, with alendronate as the first-line drug. In Denmark, reimbursement for alendronate and other alendronates requires a DXA assessment or an X-ray verified spine or hip fracture. The study was approved by the Data Protection Agency (OUH 15/ 37999) and by Statistics Denmark (ref. 705079). All statistical analyses were done on de-identified patient data merged at Statistics Denmark.

\section{Study participants and design}

All patients registered in OUHD aged 40 years or older at the age of biochemistry testing, with at least one eGFR measurement below $45 \mathrm{ml} / \mathrm{min} / 1.73 \mathrm{~m}^{2}$ (CKD stages 3B, 4 and 5), at least 2 years of follow-up data available and at least two DXA BMD measurements recorded 2 or more years apart were eligible for inclusion. Previous users of any anti-osteoporosis medication (except calcium and vitamin D supplements) in the year before eGFR testing and those with more than 1 year between the closest renal measurement (eGFR) and DXA (BMD measurement) were excluded. The first dispensation of alendronate (therapy initiation) was considered the index date for alendronates users. Participants, users of alendronate, were risk-set-matched with replacement to non-users on \pm 5 years of the year of birth at index date, meaning a non-user could be matched to several alendronate users. For every alendronate user, up to five non-users at index date were randomly selected from a large pool of non-users. Selection bias was thus minimized whilst preserving statistical power, as initial non-users could become alendronate users and will be included later as users.

\section{Exposure, outcome and confounders}

Alendronate use, defined by pharmacy dispensations in the Danish Prescriptions Register, was the main exposure. Users of alendronates were identified using pre-specified lists of ATC codes. Like prescriptions, dispensation data do not necessarily reflect treatment duration. Treatment episodes were created using a previously validated algorithm that accounts for non-adherence (or non-compliance) and defines treatment episodes of continuous exposure. Any overlapping prescriptions of the same drug were interpreted as an early collection of a repeat prescription. Any overlapping days between two prescriptions of the same drug were added to the end of the period covered by the two prescriptions. Any two prescriptions of the same drug were concatenated and considered as one prescription if the gap between the end of the first prescription and the start of the second prescription was less than 30 days.

The primary study outcome was annualized femoral neck BMD percentage change, relative to the previous or baseline $\mathrm{BMD}$, up to 3 years after alendronate use (or non-use), measured using a DXA. If more than two measurements were available, the last DXA measurement 2-3 years from the index date was considered. Any measurements within 1 year between each other were excluded, as they were unlikely to provide clinically relevant information. Secondary outcomes were similarly defined as annualized BMD percentage changes, measured at the lumbar spine and total hip. If participants had serial spine measurements, we used the vertebrae that were still assessable at the last recorded visit to calculate the rate of BMD change. A sensitivity analysis used DXA measurements taken 3-5.5 years after the index date, since change in BMD has been shown to plateau after 3 years (33).

Potential confounders were pre-identified using clinical knowledge and a literature review. Confounders were measured at baseline and included age, sex, BMI, baseline eGFR, fracture history, comorbidities (Charlson index, renal disease and diabetes), hospital contacts in the previous year and concomitant drug use (number of ATC in the year before index, aromatase inhibitors, antihypertensives, antidepressants and antidiabetics). As systemic steroids have an effect on BMD and are commonly used in certain renal conditions, we accounted for these drugs in a more granular fashion. We calculated the number of defined daily doses in the previous year and stratified into quartiles.

\section{Statistical analyses}

In a primary analysis, propensity scores for alendronate use were estimated using multivariable logistic regression, 
including the confounders (Table 1). Interactions between age and BMI as well as age and baseline eGFR were added to the propensity score equation to improve the balance of the baseline characteristics. The calculated propensity scores were used to match each alendronate user with to up to five comparable non-users with a calliper width of at most 0.02 SDs on the logit of the propensity scores. Balance before and after matching was checked using the absolute standardized mean difference (ASMD). An ASMD of 0.10 or less was considered acceptable and representative of a good balance.

Linear regression modelling was used to estimate average differences (expressed as beta coefficient and 95\% confidence intervals) in the annualized BMD change (per cent versus index measure) at the femoral neck (primary outcome), total hip and lumbar spine (secondary outcomes). Two post hoc analyses were conducted to deal with the low number of alendronate users eligible for inclusion in the final analyses:

(i) A linear regression model including all eligible alendronate users and non-users and adjusted for the previously calculated propensity scores (ii) A multivariable linear regression model, adjusting for the same set of confounders included in the propensity score model, was fitted to model annualized percentage BMD change according to alendronate use, with $95 \%$ confidence intervals.

All analyses were conducted using R (34) and STATA 15 (35). Statistical syntax was programmed at Oxford using mock data extracted from the analytical dataset. These programs were run 'in situ' by a statistician at Odense, Denmark. Final results were verified by two of the authors (MSA and DPA).

\section{Results}

\section{Participants and baseline characteristics}

We identified 36,024 patients in the linked OUHD BMD database who were eligible for the study, including 12,544 (34.8\%) patients who were alendronate users within the study period. We excluded 233 (1.9\%) who were younger than 40
Table 1 Baseline characteristics for eligible and included bisphosphonate users

\begin{tabular}{|c|c|c|}
\hline & Eligible & Included \\
\hline \multicolumn{3}{|l|}{ Characteristic } \\
\hline Unique patients $(N)$ & 270 & 71 \\
\hline eGFR, mean (SD) & $37.2(7.2)$ & $37.9(8.0)$ \\
\hline Dead within 3 years of first bisphosphonate & $35(13.0 \%)$ & $0(0.0 \%)$ \\
\hline Age, median (IQR) & $82(76-87)$ & $79(70-83)$ \\
\hline Gender, female $N(\%)$ & $268(99.3 \%)$ & $71(100.0 \%)$ \\
\hline \multicolumn{3}{|l|}{ Index $\mathrm{BMD}^{\mathrm{a}}$, mean $(\mathrm{SD})$} \\
\hline Total hip & $0.657(0.123)$ & $0.678(0.117)$ \\
\hline Femoral neck & $0.551(0.110)$ & $0.560(0.106)$ \\
\hline Spine & $0.791(0.165)$ & $0.782(0.166)$ \\
\hline \multicolumn{3}{|l|}{ Fractures, $N(\%)$} \\
\hline Hip & $21(7.8 \%)$ & $5(7.0 \%)$ \\
\hline Non-hip other & $21(7.8 \%)$ & $5(7.0 \%)$ \\
\hline Non-hip osteoporotic & $28(10.4 \%)$ & $6(8.5 \%)$ \\
\hline \multicolumn{3}{|l|}{ Charlson score, $N(\%)$} \\
\hline 0 & $142(52.6 \%)$ & $39(54.9 \%)$ \\
\hline 1 & $64(23.7 \%)$ & $18(25.4 \%)$ \\
\hline 2 & $29(10.7 \%)$ & $7(9.9 \%)$ \\
\hline$\geq 3$ & $35(13.0 \%)$ & $7(9.9 \%)$ \\
\hline \multicolumn{3}{|l|}{ Concomitant drugs, $N(\%)$} \\
\hline Systemic corticosteroids & $98(36.3 \%)$ & $29(40.8 \%)$ \\
\hline Anticoagulants & $163(60.4 \%)$ & $35(49.3 \%)$ \\
\hline Statins & $106(39.3 \%)$ & $30(42.3 \%)$ \\
\hline Antidiabetics & $38(14.1 \%)$ & $7(9.9 \%)$ \\
\hline Antihypertensives & $198(73.3 \%)$ & $58(81.7 \%)$ \\
\hline
\end{tabular}

${ }^{\mathrm{a}} \mathrm{Up}$ to 1 year before index date

$B M D$, bone mineral density; discont., discontinued; $e G F R$, estimated glomerular filtration rate; $I Q R$, interquartile range; $O P$, osteoporotic; $S D$, standard deviation 
years at the time of therapy initiation, 1323/12,544 (10.5\%) who did not have an eGFR measurement recorded in the previous year and 10,586/12,544 (84.4\%) who had an eGFR value of 45 or above. Of the remaining 402 eligible alendronate users, a third (132/402, 32.8\%) had no DXA measurement in the year before therapy initiation. Therefore, 270 alendronate users $(264,98 \%$ on alendronate) were eligible for the study (Fig. 1). Amongst these, 35 (13.0\%) died during follow-up, 93 (34.4\%) discontinued alendronate therapy before having a repeat BMD and $142(52.6 \%)$ did not have a repeat BMD between 1 and 3.5 years after the first scan after therapy started. We, therefore, included 71 alendronate users in the study. In parallel, 23,713 non-users were initially available for comparison. Amongst these, 1228 (5.2\%) died during follow-up. Only 1609 (6.8\%) had repeat BMD measures between 1 and 3.5 years after their index DXA and were eligible for the analysis.

Baseline characteristics for all 270 eligible alendronate users and the final sample of 71 are reported in Table 1 . As expected, participants included in the final analyses were younger ( 79 verses 82 years old on average), healthier (54.9\% versus $52.6 \%$ with a Charlson score of 0 ) and more likely to use systemic corticosteroids ( $40.8 \%$ versus $36.3 \%$ ), statins $(42.3 \%$ versus $39.3 \%)$ and antihypertensives $(81.7 \%$ versus $73.3 \%$ ) than those excluded.

Table 2 reports baseline characteristics for the included participants, stratified by alendronate use. Both groups only included women and had an average age of 79-80 years. As expected, alendronate users had a much lower index BMD ( 0.56 versus $0.62 \mathrm{~g} / \mathrm{cm}^{2}$ at the femoral neck), were more likely
Fig. 1 Construction of treatment episodes based on prescription data. Most of the eligible patients were on alendronate $(264 / 270$, $98 \%)$

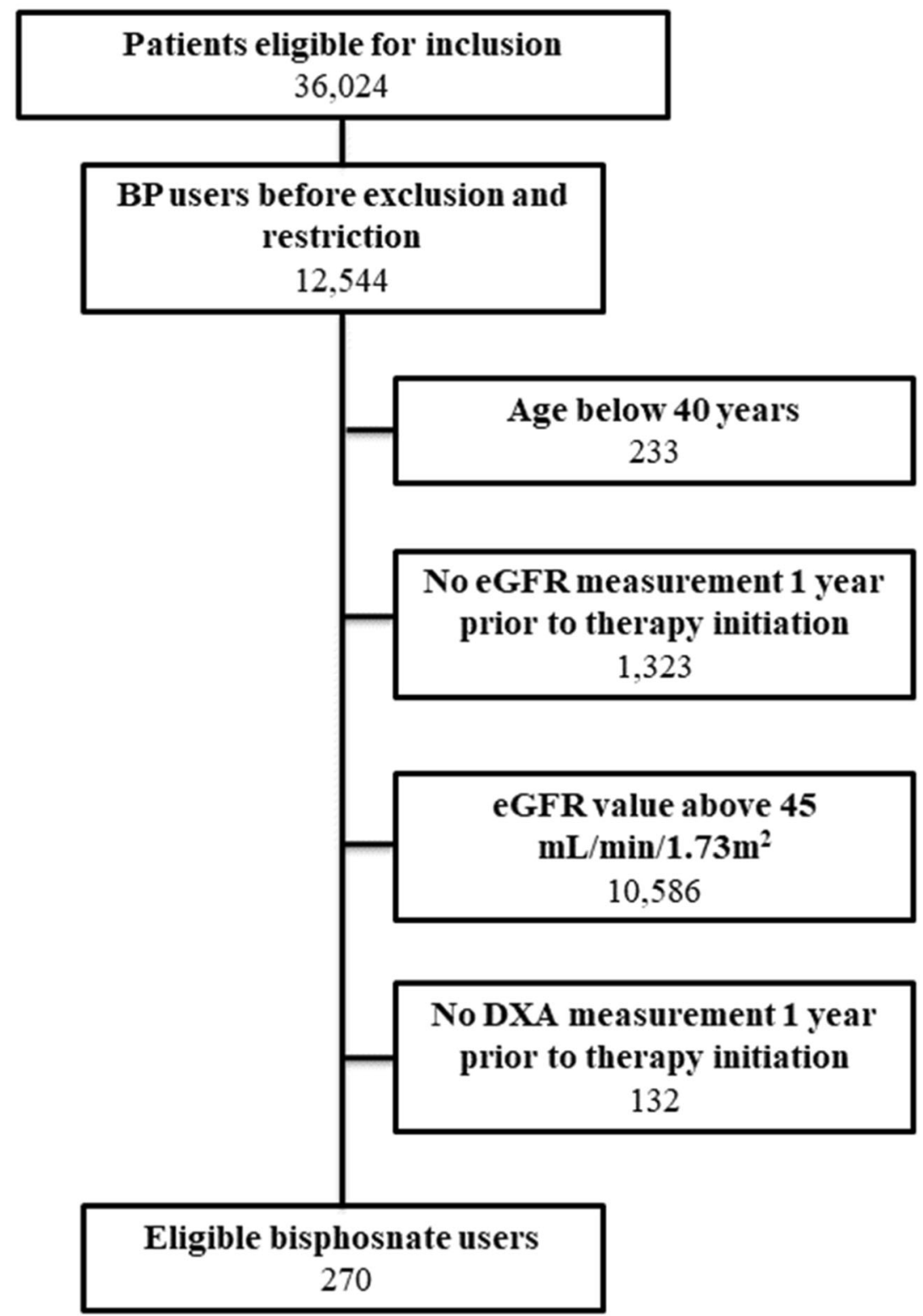


Table 2 Baseline characteristics according to bisphosphonate use

\begin{tabular}{|c|c|c|c|c|}
\hline & \multicolumn{2}{|c|}{ Before matching } & \multicolumn{2}{|l|}{ After matching } \\
\hline & Users & Non-users & Users & Non-users \\
\hline Patients $(N)$ & 71 & $1492^{\mathrm{a}}$ & 40 & 142 \\
\hline eGFR, mean (SD) & $37.9(8.0)$ & $36.1(7.7)$ & $37.1(9.1)$ & $38.0(6.7)$ \\
\hline Age, median (IQR) & $79(70-83)$ & $80(76-85)$ & $79(75-82)$ & $79(73-84)$ \\
\hline \multicolumn{5}{|l|}{ Gender, $N(\%)$} \\
\hline Females & $71(100 \%)$ & $1492(100 \%)$ & $40(100.0 \%)$ & $142(100.0 \%)$ \\
\hline Males & $0(0 \%)$ & $0(0 \%)$ & $0(0 \%)$ & $0(0 \%)$ \\
\hline \multicolumn{5}{|l|}{ Bone mineral density } \\
\hline Total hip & $0.678(0.117)$ & $0.754(0.144)$ & $0.663(0.119)$ & $0.738(0.134)$ \\
\hline Femoral neck & $0.560(0.106)$ & $0.627(0.121)$ & $0.547(0.104)$ & $0.617(0.104)$ \\
\hline Spine & $0.782(0.166)$ & $0.877(0.171)$ & $0.806(0.146)$ & $0.881(0.176)$ \\
\hline \multicolumn{5}{|l|}{ Fractures, $N(\%)$} \\
\hline Hip & $5(7.0 \%)$ & $28(1.9 \%)$ & $5(12.5 \%)$ & $(n<5)$ \\
\hline Non-hip other & $5(7.0 \%)$ & $99(6.6 \%)$ & $(n<5)$ & $(n<5)$ \\
\hline Non-hip osteoporotic & $6(8.5 \%)$ & $89(6.0 \%)$ & $(n<5)$ & $6(4.2 \%)$ \\
\hline \multicolumn{5}{|l|}{ Charlson score, $N(\%)$} \\
\hline 0 & $39(54.9 \%)$ & $778(52.1 \%)$ & $27(67.5 \%)$ & $95(66.9 \%)$ \\
\hline 1 & $18(25.4 \%)$ & $322(21.6 \%)$ & $8(20.0 \%)$ & $23(16.2 \%)$ \\
\hline 2 & $7(9.9 \%)$ & $213(14.3 \%)$ & $(n<5)$ & $9(6.3 \%)$ \\
\hline$\geq 3$ & $7(9.9 \%)$ & $179(12.0 \%)$ & $(n<5)$ & $8(5.6 \%)$ \\
\hline \multicolumn{5}{|l|}{ Drugs, $N(\%)$} \\
\hline Systemic corticosteroids & $29(40.8 \%)$ & $493(33.0 \%)$ & $11(27.5 \%)$ & $51(35.9 \%)$ \\
\hline Anticoagulants & $35(49.3 \%)$ & $818(54.8 \%)$ & $18(45.0 \%)$ & $61(43.0 \%)$ \\
\hline Statins & $30(42.3 \%)$ & $522(35.0 \%)$ & $17(42.5 \%)$ & $51(35.9 \%)$ \\
\hline Antidiabetics & $7(9.9 \%)$ & $316(21.2 \%)$ & $5(12.5 \%)$ & $26(18.3 \%)$ \\
\hline Antihypertensives & $58(81.7 \%)$ & $1.331(75.8 \%)$ & $32(80.0 \%)$ & $112(78.9 \%)$ \\
\hline \multicolumn{5}{|l|}{ Additional diagnoses, $N(\%)$} \\
\hline Diabetes (uncomplicated) & $5(7.0 \%)$ & $171(11.5 \%)$ & $(n<5)$ & $16(11.3 \%)$ \\
\hline Diabetes with complications & $(n<5)$ & $30(2.0 \%)$ & $(n<5)$ & $(n<5)$ \\
\hline Dementia & $(n<5)$ & $40(2.7 \%)$ & $(n<5)$ & $(n<5)$ \\
\hline Cardiovascular disease & $(n<5)$ & $17(1.1 \%)$ & $0(0 \%)$ & $(n<5)$ \\
\hline Hypertension & $16(22.5 \%)$ & $328(22.0 \%)$ & $7(17.5 \%)$ & $26(18.3 \%)$ \\
\hline COPD & $8(11.3 \%)$ & $143(9.6 \%)$ & $(n<5)$ & $14(9.9 \%)$ \\
\hline Heart failure & $17(23.9 \%)$ & $383(25.7 \%)$ & $8(20.0 \%)$ & $27(19.0 \%)$ \\
\hline Renal transplant & $0(0.0 \%)$ & $6(0.4 \%)$ & $0(0 \%)$ & $0(0 \%)$ \\
\hline Renal dialysis & $0(0.0 \%)$ & $20(1.3 \%)$ & $0(0 \%)$ & $0(0 \%)$ \\
\hline
\end{tabular}

${ }^{\text {a }} 1492$ episodes in 206 unique patients

$C O P D$, chronic obstructive pulmonary disease; $e G F R$, estimated glomerular filtration rate; $I Q R$, interquartile range; $S D$, standard deviation

to use systemic corticosteroids (40.8\% versus 32.8 ) and had a much higher prevalence of the previous fracture $(7.0 \%$ versus $1.7 \%$ for hip fracture history) than non-users. Low bone mass, prevention of glucocorticoid-induced osteoporosis and secondary fracture prevention are the most likely indicators of alendronates in patients with moderate-to-severe CKD. All of these variables and the confounders listed in Table 1 are adjusted for using propensity score and multivariable regression models.

\section{Propensity score matching}

Before matching, the two groups had little overlap in their propensity scores, with median (interquartile range) of 0.49 $(0.17,0.84)$ for the alendronate users and below $0.001(<$ $0.001,0.003)$ for the non-users. After matching, the median (IQR) of the propensity scores were more similar, at 0.19 $(0.08,0.43)$ in the alendronate users and $0.13(0.04,0.43)$ in non-users. 
Forty of the 71 alendronate users were matched to 142 nonusers. Matching improved balance and reduced differences to acceptable limits (ASMD < 0.1) for most of the assessed participant characteristics included in the model (Fig. 2). However, relevant differences remained for key confounders, including baseline (index) femoral neck BMD (0.55 versus $0.62 \mathrm{gr} / \mathrm{cm}^{2}$ ), use of systemic glucocorticoids $(27.5 \%$ versus $35.9 \%)$ and previous hip fracture history (12.5\% versus $3.5 \%$ ). Charlson comorbidity index, polypharmacy, number of hospital visits, history of key comorbid conditions (complicated diabetes, hypertension, chronic heart failure and COPD) and previous use of antiepileptics or antidiabetic therapies also still had unacceptable imbalances (ASMD > 0.1) after matching. Matching excluded more than $91 \%$ of the potentially eligible alendronate non-users.

\section{Annualized bone mineral density changes over time}

In the propensity-matched cohorts (pre-specified primary analysis), alendronate non-users lost on average $1.59 \%$ of their baseline femoral neck BMD per year, whereas alendronate users increased their BMD by $1.07 \%$ per year of therapy. The average percentage BMD changes in the propensity-score-matched cohort are detailed in Table 3. In a linear regression model, after propensity score matching, the mean difference $(95 \% \mathrm{CI})$ in percentage annual change in femoral neck BMD between alendronate users and nonusers favoured the users by $+2.65 \%(1.32 \%, 3.99 \%)$ per year of alendronate exposure. Average femoral neck BMD change per month for alendronate non-users and users is shown in Fig. 3a.

In the analyses including the full cohort, alendronate nonusers lost on average $1.67 \%$ of their baseline femoral neck BMD per year, whereas alendronate users gained an average $0.63 \%$ per year on treatment. The results of linear regression modelling supported the findings from the propensitymatched analysis, with a multivariable-adjusted beta coefficient (mean difference between groups) of $+2.14 \%(1.22 \%$, $3.05 \%)$ and a propensity-score-adjusted beta of $+2.15 \%$ $(0.97 \%, 3.34 \%)$ per year.

In the analysis of secondary outcomes, BMD at the spine increased amongst alendronate users by $3.98 \%$ per year for the full cohort and by $3.36 \%$ in the propensitymatched cohort. Alendronate non-users in the full cohort increased their BMD by $0.65 \%$ per year and in the matched cohort by $0.34 \%$ per year. The mean $(95 \% \mathrm{CI})$ difference in percentage BMD change was again in favour of alendronate users, with betas of $+3.01 \%(1.74 \%, 4.28 \%)$ per year for the propensity-score-matched analysis, + $2.14 \%(1.22 \%, 3.05 \%)$ for the multivariable analysis and

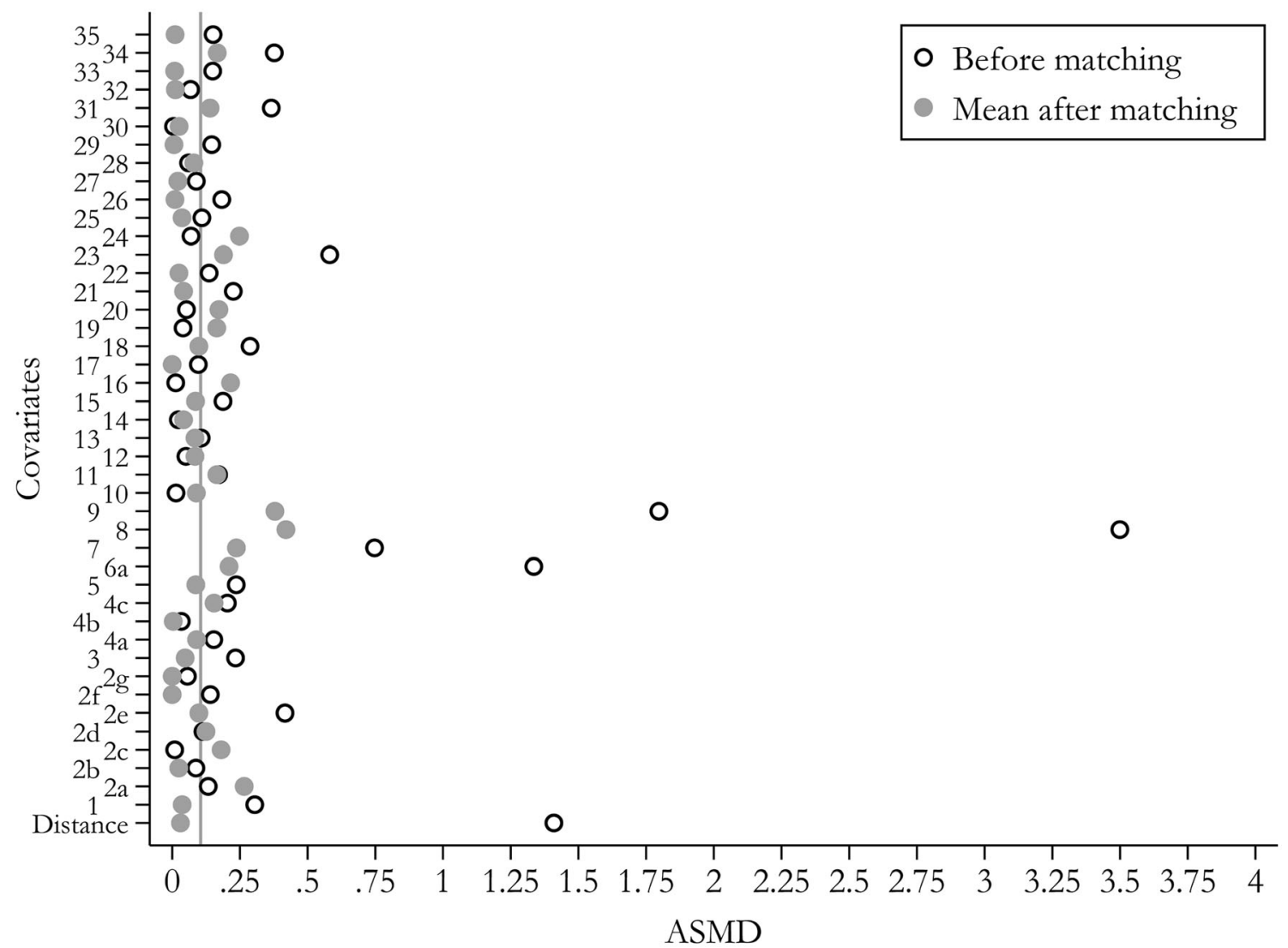

Fig. 2 Covariate balance before and after matching usiung ASMD 
Table 3 Results of the analysis of bone mineral density (BMD) changes in participants exposed and unexposed to bisphosphonates

\begin{tabular}{|c|c|c|c|c|c|c|}
\hline & \multirow[t]{2}{*}{ Analysis } & \multicolumn{2}{|c|}{ Non-user } & \multicolumn{2}{|c|}{ User } & \multirow[t]{2}{*}{ Mean difference $(95 \% \mathrm{CI})$} \\
\hline & & $N$ & BMD change & $N$ & BMD change & \\
\hline \multirow[t]{3}{*}{ Femoral neck } & PS-matched & 142 & -1.59 & 40 & 1.07 & $2.65(1.32,3.99)$ \\
\hline & Multivariable & 1492 & -1.67 & 71 & 0.63 & $2.14(1.22,3.05)$ \\
\hline & PS-adjusted & 1492 & -1.67 & 71 & 0.63 & $2.15(0.97,3.34)$ \\
\hline \multirow[t]{3}{*}{ Spine } & PS-matched & 142 & 0.34 & 40 & 3.36 & $3.01(1.74,4.28)$ \\
\hline & Multivariable & 1492 & 0.65 & 71 & 3.98 & $2.14(1.22,3.05)$ \\
\hline & PS-adjusted & 1492 & 0.65 & 71 & 3.98 & $2.87(1.62,4.12)$ \\
\hline \multirow[t]{3}{*}{ Total hip } & PS-matched & 142 & -1.16 & 40 & 0.95 & $2.12(0.98,3.25)$ \\
\hline & Multivariable & 1492 & -2.14 & 71 & 0.82 & $2.29(1.46,3.11)$ \\
\hline & PS-adjusted & 1492 & -2.14 & 71 & 0.82 & $1.91(0.82,3.00)$ \\
\hline
\end{tabular}

$P S$, propensity score
$+2.87 \%(1.62 \%, 4.12 \%)$ for the propensity-score-adjusted analysis. Average spine BMD change per month for alendronate non-users and users is shown in Fig. $3 b$.

Total hip BMD improved by an average of $0.82 \%$ per year for the full cohort of alendronate users and by $0.95 \%$ for the matched cohort. Alendronate non-users in the full cohort lost on average $-2.14 \%$ BMD per year and those in the propensity-matched cohort lost $-1.16 \%$ per year. The mean difference was $+2.12(0.98 \%, 3.25 \%)$ per year in favour of alendronate users in the propensity-score-matched model, + $2.29 \%(1.46 \%, 3.11 \%)$ for the multivariable model and + $1.91 \%(0.82 \%, 3.00 \%)$ for the propensity-adjusted model. Average hip bone mineral density (BMD) change per month for alendronate non-users and users is shown in Fig. 3c.

The pre-specified sensitivity analysis using DXA measures taken between 3 and 5.5 years after index date could not be performed in the matched analysis as only 1 alendronate user and 12 non-users had valid follow-up data in this time window.

\section{Discussion}

We used region-wide population-based data from Funen, Denmark. Despite the size of the source dataset, only $71 \mathrm{fe}-$ male participants were identified with stage 3B-5 CKD who were given alendronates, continued the treatment for at least 1 year and had at least two recorded BMD measurements. From around 200 eligible participants not using alendronates, only 1609 records of BMD measurements at different times were available. Propensity score matching led to the exclusion of almost half of the users and more than $90 \%$ of the non-users. Although matching helped to reduce confounding, imbalance remained when alendronate users and matched non-users were compared, including in key confounders such as baseline BMD, fracture history and use of systemic steroids. The small sample might demonstrate the low likelihood of Danish patients with stage $3 \mathrm{~B}-5 \mathrm{CKD}$ being prescribed alendronates, reflecting the safety concerns and lack of evidence on the efficacy that led to this study.

The primary propensity-matched cohort analysis identified a significant, clinically relevant effect, with a $+1.1 \%$ femoral neck BMD gain per year in alendronate users, compared with $\mathrm{a}-1.6 \%$ bone loss at the same site per year in matched nonusers. This is equivalent to $\mathrm{a}+2.7 \%$ difference in BMD change per year in favour of alendronate users. The full cohort multivariable and propensity adjustment analyses found consistent results, with $\mathrm{a}+2.1 \%$ and $+2.65 \%$ difference per year favouring alendronate use, respectively. Consistent results were found for the secondary outcomes. Lumbar spine and total hip BMD improved by $3.4 \%$ and $1.0 \%$ per year in alendronate users, compared with that by $0.3 \%$ and $-1.2 \%$ (bone loss) per year in the propensity-score-matched nonusers, respectively. This equated to a significant $+3.0 \%$ per year average difference in the lumbar spine and $a+2.1 \%$ difference in the total hip, both favouring alendronate users. Multivariable and propensity-adjusted models found similar results.

\section{Limitations and strengths}

This cohort analysis has limitations. The eligibility criteria excluded most of the records in the database including male patients and users of other oral bisphosphonates. Although this was not surprising, as bisphosphonates are to be used with caution in patients with stage 3 CKD and are contraindicated in stages 4 and 5 , it is possible that the generalizability of the findings might have been compromised. The need for repeat DXA testing to obtain BMD change over time, the outcome of interest in this study, excluded more than half of the potentially eligible bisphosphonate users. These patients may have differed from the included participants, as BMD monitoring during treatment is not routine practice in actual care conditions. 

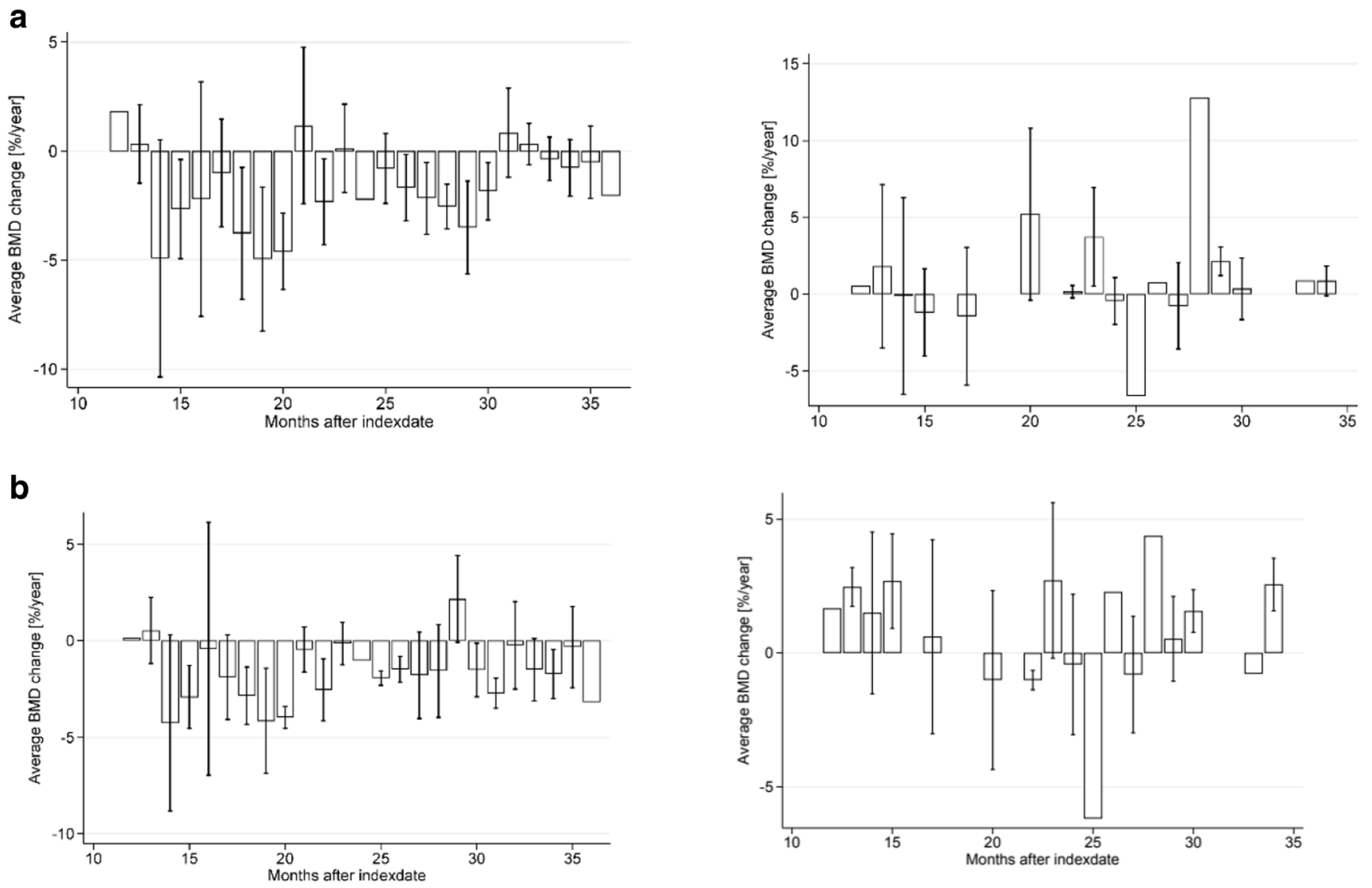

\section{C}
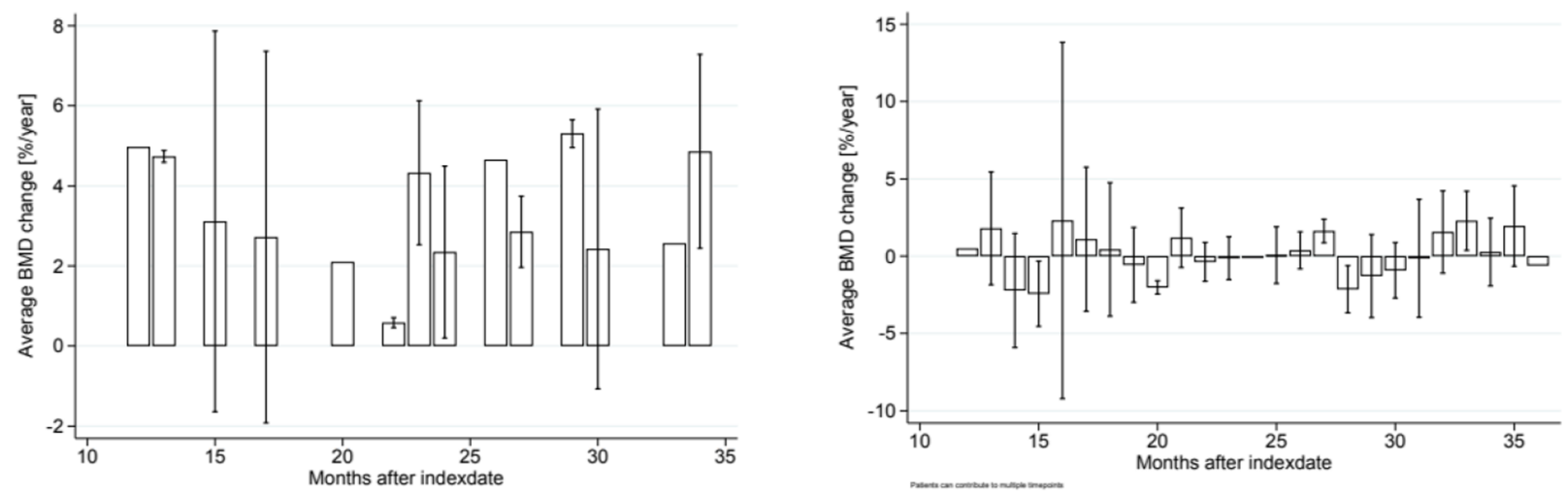

Fig. 3 Average bone mineral density (BMD) change per month for bisphosphonate users (left) and non-users (right) in the femoral neck (a), hip (b) and spine (c)

Current evidence suggests that routine monitoring of BMD within 3 years of starting bisphosphonates in postmenopausal women is clinically unhelpfull (36) and may contribute to a lack of follow-up densitometry in an unexpectedly large proportion of those treated. Trials of bisphosphonates have shown a significant attenuation of BMD gain after the first 12 months of therapy $(15,37)$. The overlap between alendronate users and non-users was small, excluding almost half of the alendronate users and over $90 \%$ of the non-users when propensity score matching was applied.
However, the multivariable and propensity adjustment models that include the full cohort gave reassuringly similar estimates to the propensity-matched analysis. Only women were included in these analyses, possibly related to the high rate of exclusion. The findings are thus limited to the female population.

This analysis also has some strengths. The dataset used has high granularity and quality and comprises information from a number of linked data sources. It is a unique data source for research as it includes comorbidity, hospital contacts, biochemistry, drug use, BMD testing and related questionnaires 
(38). The dataset also includes most of the population of a whole region of Denmark, thus maximizing the external validity of our findings.

The observed differences in femoral neck BMD in alendronate user versus non-user participants over 1 year were similar to those observed in trials of postmenopausal women (15). However, our alendronate users had only half the increase in BMD seen in the trial's treatment arm after 1 year of therapy, where the increase in femoral neck BMD was $2 \%$ with alendronate (15). Although not statistically significant, the total hip is certainly the most relevant site of the upper extremity of the femur in the context of a follow-up with or without treatment. It is difficult to make generalization given the small size of our study in the findings. The difference at the spine in our alendronate users was also smaller than seen in the trial, where there was a $4.2 \%$ increase after 1 year. It is difficult to compare our unexposed CKD participants with those in the placebo arm of the trial as the trial participants who received the placebo also received calcium and vitamin $\mathrm{D}$ supplements.

Early BMD changes during therapy are difficult to interpret due to regression to the mean (39) with most patients who lose BMD in the first year of alendronate therapy going on to have significant increases in BMD in the second year. Our attempt to address this issue in a sensitivity analysis was inhibited due to a lack of power. The relationship between BMD change and fracture risk may differ in postmenopausal osteoporosis and bone fragility in CKD as they have different aetiopathology, with the potential involvement of adynamic bone disease in bone fragility in CKD (26). The disconnect between treatment-related BMD increases and fracture risk is exemplified in trials of fluoride therapy, where increased BMD was associated with a paradoxical increased risk of fracture (40). The artefactual effects of vascular calcification on spinal BMD further complicate the interpretation of BMD in patients with CKD (41).

\section{Conclusions}

We demonstrated that alendronate therapy had a positive effect on BMD in female patients with stage 3B-5 CKD. BMD is the best surrogate available for bone strength in clinical practice, and RCTs using BMD as a primary outcome have been accepted by regulators as bridge studies to extend the indication of alendronate therapies for men (25) and for the prevention or treatment of steroid-induced osteoporosis (38). We found that BMD improved more (by $2 \%$ to $3 \%$ per year, depending on skeletal site) in alendronate users than non-users. In fact, BMD decreased over time when participants were off alendronate therapy, by about $1 \%$ per year in the femoral neck and total hip. The result had an average difference of
$+2.7 \%,+3 \%$ and $+2.1 \%$ BMD change per year in the femoral neck, lumbar spine and total hip, respectively, all in favour of alendronate users. These findings were not modified by age, previous fracture history or baseline renal function.

Funding information This project was funded by the NIHR HTA (project number or 14/36/02) and supported by the NIHR Biomedical Research Centre, Oxford.

Compliance with ethical standards The study was approved by the Data Protection Agency (OUH 15/37999) and by Statistics Denmark (ref. 705079). All statistical analyses were done on deidentified patient data merged at Statistics Denmark.

Conflicts of interest NK Arden reports personal fees from Flexion, Freshfields, Janssen, Merck and Regeneron. C Cooper reports lecture fees and honoraria from the Alliance for Better Bone Health Amgen, Eli Lilly, GSK, Medtronic, Merck, Novartis, Pfizer, Roche, Servier, Takeda and UCB. A Judge is a subpanel member of the NIHR PGfAR, has received consultancy fees from Freshfields Bruckhaus Deringer and has held advisory board positions (which involved receipt of fees) at Anthera Pharmaceuticals, INC. MK Javaid reports research support and speaker fees from Amgen. D Prieto-Alhambra reports research grants from UCB, Amgen and Les Laboratoires Servier and (not personal) speaker and consultancy fees from UCB and Amgen. D Prieto-Alhambra is a member of the NIHR HTA CET panel since November 2017. DE Robinson, MS Ali, KRubin, M Ernst, P Hermann, M Nybo, Y Ben-Shlomo and F Caskey have nothing to disclose. The views expressed are those of the authors and not necessarily those of the NHS, NIHR or Department of Health.

Open Access This article is licensed under a Creative Commons Attribution 4.0 International License, which permits use, sharing, adaptation, distribution and reproduction in any medium or format, as long as you give appropriate credit to the original author(s) and the source, provide a link to the Creative Commons licence, and indicate if changes were made. The images or other third party material in this article are included in the article's Creative Commons licence, unless indicated otherwise in a credit line to the material. If material is not included in the article's Creative Commons licence and your intended use is not permitted by statutory regulation or exceeds the permitted use, you will need to obtain permission directly from the copyright holder. To view a copy of this licence, visit http://creativecommons.org/licenses/by/4.0/.

\section{References}

1. Anandarajah S, Tai T, de Lusignan S, Stevens P, O'Donoghue D, Walker M, Hilton S (2005) The validity of searching routinely collected general practice computer data to identify patients with chronic kidney disease (CKD): a manual review of 500 medical records. Nephrol Dial Transplant 20(10):2089-2096

2. Najar MS, Mir MM, Muzamil MM et al (2017) Prevalence of osteoporosis in patients with chronic kidney disease (stages 3-5) in comparison with age-and sex-matched controls: a study from Kashmir valley tertiary care center. Saudi J Kidney Dis Transpl 28(3):538-544

3. Nickolas TL, Stein EM, Dworakowski E, Nishiyama KK, Komandah-Kosseh M, Zhang CA, McMahon DJ, Liu XS, Boutroy S, Cremers S, Shane E (2013) Rapid cortical bone loss 
in patients with chronic kidney disease. J Bone Miner Res 28(8): $1811-1820$

4. Ensrud KE, Lui LY, Taylor BC, Ishani A, Shlipak MG, Stone KL, Cauley JA, Jamal SA, Antoniucci DM, Cummings SR, Osteoporotic Fractures Research Group (2007) Renal function and risk of hip and vertebral fractures in older women. Arch Gen Intern Med 167(2):133-139

5. Dooley AC, Weiss NS, Kestenbaum B (2008) Increased risk of hip fracture among men with CKD. Am J Kidney Dis 51(1):38-44

6. Maravic M, Ostertag A, Urena P, Cohen-Solal M (2016) Dementia is a major risk factor for hip fractures in patients with chronic kidney disease. Osteoporos Int 27(4):1665-1669

7. Alem AM, Sherrard DJ, Gillen DL, Weiss NS, Beresford SA, Heckbert SR, Wong C, Stehman-Breen C (2000) Increased risk of hip fracture among patients with end-stage renal disease. Kidney Int 58(1):396-399

8. Hansen D, Olesen JB, Gislason GH, Abrahamsen B, Hommel K (2016) Risk of fracture in adults on renal replacement therapy: a Danish national cohort study. Nephrol Dial Transplant 31(10): 1654-1662

9. Thomas R, Kanso A, Sedor JR (2008) Chronic kidney disease and its complications. Prim Care 35(2):329-344

10. Fujiwara S, Kasagi F, Masunari F (2003) Fracture prediction from bone mineral density in Japanese men and women. J Bone Miner Res 18(8):1547-1553

11. Jiang C, Giger ML, Kwak SM, Chinander MR, Martell JM, Favus MJ (2000) Normalized BMD as a predictor of bone strength. Acad Radiol 7(1):33-39

12. Iimori S, Mori Y, Akita W et al (2011) Diagnostic usefulness of bone mineral density and biochemical markers of bone turnover in predicting fracture in CKD stage 5D patients - a single-center cohort study. Nephrol Dial Transplant 27(1):345-351

13. Yenchek RH, Ix JH, Shlipak MG, Bauer DC, Rianon NJ, Kritchevsky SB, Harris TB, Newman AB, Cauley JA, Fried LF, for the Health, Aging, and Body Composition Study (2012) Bone mineral density and fracture risk in older individuals with CKD. Clin J Am Soc Nephrol 7(7):1130-1136

14. West SL, Lok CE, Langsetmo L, Cheung AM, Szabo E, Pearce D, Fusaro M, Wald R, Weinstein J, Jamal SA (2015) Bone mineral density predicts fractures in chronic kidney disease. J Bone Miner Res 30(5):913-919

15. Black DM, Cummings SR, Karpf DB, Cauley JA, Thompson DE, Nevitt MC, Bauer DC, Genant HK, Haskell WL, Marcus R, Ott SM, Torner JC, Quandt SA, Reiss TF, Ensrud KE (1996) Randomised trial of effect of alendronate on risk of fracture in women with existing vertebral fractures. Lancet 348(9041):15351541

16. Cummings SR, Black DM, Thompson DE, Applegate WB, BarrettConnor E, Musliner TA, Palermo L, Prineas R, Rubin SM, Scott JC, Vogt T, Wallace R, Yates AJ, LaCroix A (1998) Effect of alendronate on risk of fracture in women with low bone density but without vertebral fractures: results from the fracture intervention trial. JAMA 280(24):2077-2082

17. McClung M, Clemmesen B, Daifotis A, Gilchrist NL, Eisman J, Weinstein RS, Fuleihan G el-H, Reda C, Yates AJ, Ravn P (1998) Alendronate prevents postmenopausal bone loss in women without osteoporosis: a double-blind, randomized, controlled trial. Ann Intern Med 128(4):253-261

18. Siris E, Adler R, Bilezikian J et al (2014) The clinical diagnosis of osteoporosis: a position statement from the national bone health alliance working group. Osteoporos Int 25(5):1439-1443
19. McClung MR, Geusens P, Miller PD et al (2001) Effect of risedronate on the risk of hip fracture in elderly women. N Engl J Med 344(5):333-340

20. Hochberg MC, Ross PD, Black D, Cummings SR, Genant HK, Nevitt MC, Barrett-Connor E, Musliner T, Thompson D, for the Fracture Intervention Trial Research Group (1999) Larger increases in bone mineral density during alendronate therapy are associated with a lower risk of new vertebral fractures in women with postmenopausal osteoporosis. Arthritis Rheum 42(6):1246-1254

21. Ott MS (2012) Bisphosphonate safety and efficacy in chronic kidney disease. Kidney Int 82(8):833-835

22. Bouxsein ML, Delmas PD (2008) Considerations for development of surrogate endpoints for anti-fracture efficacy of new treatments in osteoporosis: a perspective. J Bone Miner Res 23(8):1155-1167

23. Schnitzer T, Bone H, Crepaldi GF et (2000) Therapeutic equivalence of alendronate $70 \mathrm{mg}$ once weekly and alendronate $10 \mathrm{mg}$ daily in the treatment of osteoporosis. Aging Clin Exp Res 12(1): 1-12

24. Orwoll E, Ettinger M, Weiss S, Miller P, Kendler D, Graham J, Adami S, Weber K, Lorenc R, Pietschmann P, Vandormael K, Lombardi A (2000) Alendronate for the treatment of osteoporosis in men. N Engl J Med 343(9):604-610

25. Saag KG, Emkey R, Schnitzer TJ et al (1998) Alendronate for the prevention and treatment of glucocorticoid-induced osteoporosis. N Engl J Med 339(5):92-299

26. Iwasaki Y, Kazama JJ, Fukagawa M (2017) Molecular abnormalities underlying bone fragility in chronic kidney disease. Biomed Res Int 2017:1-11. https://doi.org/10.1155/2017/3485785

27. Levey AS, Stevens LA, Schmid CH, Zhang Y(L), Castro AF III, Feldman HI, Kusek JW, Eggers P, van Lente F, Greene T, Coresh J, for the CKD-EPI (Chronic Kidney Disease Epidemiology Collaboration) (2009) A new equation to estimate glomerular filtration rate. Ann Intern Med 150(9):604-612

28. Abrahamsen B, Jørgensen HL, Laulund AL et al (2014) Low serum thyrotropin level and duration of suppression as a predictor of major osteoporotic fractures - the open thyro register cohort. J Bone Miner Res 29(9):2040-2050

29. Abrahamsen B, Jørgensen HL, Laulund AS, Nybo M, Bauer DC, Brix TH, Hegedüs L (2015) The excess risk of major osteoporotic fractures in hypothyroidism is driven by cumulative hyperthyroid as opposed to hypothyroid time: an observational register-based time-resolved cohort analysis. J Bone Miner Res 30(5):898-905

30. Rubin KH, Glintborg D, Nybo M, Andersen M, Abrahamsen B (2016) Fracture risk is decreased in women with polycystic ovary syndrome: a register-based and population-based cohort study. J Bone Miner Res 31(4):709-717

31. Praetorius K, Madsen CM, Abrahamsen B, Jørgensen HL, Lauritzen JB, Laulund ASB (2016) Low levels of hemoglobin at admission are associated with increased 30-day mortality in patients with hip fracture. Geriatr Orthop Surg Rehabil 7(3):115-120

32. Händel MN, Frederiksen $\mathrm{P}$, Cohen A, Cooper C, Heitmann BL, Abrahamsen B (2017) Neonatal vitamin d status from archived dried blood spots and future risk of fractures in childhood: results from the D-tect study, a population-based case-cohort study. Am J Clin Nutr 106(1):155-161

33. Black DM, Schwartz AV, Ensrud KE, Cauley JA, Levis S, Quandt SA, Satterfield S, Wallace RB, Bauer DC, Palermo L, Wehren LE, Lombardi A, Santora AC, Cummings SR, FLEX Research Group (2006) Effects of continuing or stopping alendronate after 5 years of treatment: the fracture intervention trial long-term extension (flex): a randomized trial. JAMA 296(24):2927-2938 
34. R Core Team (2017) R: a language and environment for statistical computing, R Foundation for Statistical Computing, Vienna, Austria. URL https://www.R-project.org/

35. StataCorp (2017) Stata Statistical Software: Release 15 College Station, StataCorp LP, TX

36. Prieto-Alhambra D, Lalmohamed A, Abrahamsen B, Arden NK, de Boer A, Vestergaard P, de Vries F (2014) Oral bisphosphonate use and total knee/hip implant survival: validation of results in an external population-based cohort. Arthritis Rheum 66(11):3233-3240

37. Harris ST, Watts NB, Genant HK, McKeever C, Hangartner T, Keller M, Chesnut CH 3rd, Brown J, Eriksen EF, Hoseyni MS, Axelrod DW, Miller PD (1999) Effects of risedronate treatment on vertebral and non-vertebral fractures in women with postmenopausal osteoporosis: a randomized controlled trial. JAMA 282(14): 1344-1352

38. Rubin KH, Abrahamsen B, Hermann AP, Bech M, Gram J, Brixen K (2011) Prevalence of risk factors for fractures and use of DXA scanning in Danish women: a regional population-based study. Osteoporos Int 22(5):1401-1409
39. Cummings SR, Palermo L, Browner W, Marcus R, Wallace R, Pearson J, Blackwell T, Eckert S, Black D (2000) Monitoring osteoporosis therapy with bone densitometry: misleading changes and regression to the mean. JAMA 283(10):1318-1132

40. Riggs BL, Hodgson SF, O'fallon WM et al (1990) Effect of fluoride treatment on the fracture rate in postmenopausal women with osteoporosis. N Engl J Med 322(12):802-809

41. Kinsella S, Murphy K, Breen M, O'Neill S, McLaughlin P, Coyle J, Bogue C, O'Neill F, Moore N, McGarrigle AM, Molloy MG, Maher MM, Eustace JA (2015) Comparison of single CT scan assessment of bone mineral density, vascular calcification and fat mass with standard clinical measurements in renal transplant subjects: the ABC heart study. BMC Nephrol 16(1):188

Publisher's note Springer Nature remains neutral with regard to jurisdictional claims in published maps and institutional affiliations. 